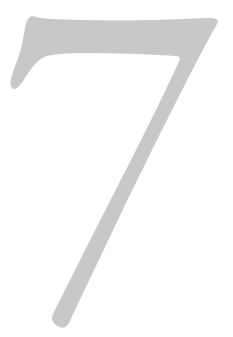

\title{
¿ DESCENTRALIZAR O \\ DESCONCENTRAR?: \\ URUGUAY FRENTE A UN DILEMA NO RESUELTO
}

DECENTRALIZE OR DECENTRALIZE?: URUGUAY FACING A DILEMMA NOT RESOLVED

\author{
ÓSCAR OSZLAK ${ }^{1}$ \\ Recibido: 19/11/2013 \\ Aceptado:25/02/2014
}

\section{RE S U M E N}

El presente trabajo analiza, en primer lugar, algunas opciones de política que el gobierno uruguayo podría considerar, en caso de que decidiera avanzar en la descentralización de su gestión hacia los gobiernos departamentales. $Y$ en segundo lugar, plantea algunas recomendaciones al respecto, que surgen de la investigación efectuada a partir de un proyecto de consultoría desarrollado en ese país ${ }^{2}$.

\section{PA L A R A S C L A E \\ Descentralización - Desconcentración - gobiernos departamentales - Uruguay.}

\footnotetext{
1. Contador Público Nacional y Licenciado en Economía (Universidad de Buenos Aires), Master en Administración Pública y Doctor en Ciencias Políticas (Universidad de California, Berkeley) y Doctor en Ciencias Económicas (Universidad de Buenos Aires). Director Maestría Administración Pública UBA, Investigador Superior CONICET, Presidente de la Red INPAE y docente en diversas universidades. Buenos Aires, Argentina.Correo electrónico: oszlak@cedes.org

2. La consultoría se desarrolló durante el año 2011 en el marco del Proyecto Procedimiento Negociado 002-010/ Entidad: 01 "Estudios en las áreas de descentralización, desarrollo económico y social, políticas públicas y desarrollo sustentable", Lote 4, "Descentralización de políticas sectoriales de competencia nacional hacia el segundo nivel de gobierno", Uruguay Integra, OPP, Uruguay. Agradezco a la Oficina Nacional de Planeamiento y Presupuesto la autorización para publicar una versión levemente modificada de mi informe original.
} 


\section{A B S T R A C T}

This paper examines, first, some policy options that the Uruguayan government could consider, in case he decided to advance the decentralization of management to departmental governments. And secondly, it raises some recommendations, arising from research conducted from a consulting project developed in that country.

\section{K E Y W O R D S}

Decentralization - Devolution - departmental governments - Uruguay.

\section{LOS TÉRMINOS DEL D ILEMA}

El dilema que plantea el título de este artículo tiene directa relación con la respuesta que Uruguay pueda dar a dos de sus problemas fundamentales en el plano institucional: el exacerbado centralismo de la gestión pública y la desarticulada actuación del gobierno nacional en el territorio.

Descentralizar, como es sabido, significa transferir poder, cometidos y recursos a los gobiernos subnacionales de segundo nivel y, eventualmente, de tercer nivel. Al menos, ésta es la definición firmemente establecida en la literatura al referirse a este concepto, sin perjuicio de admitir que en Uruguay ha sido utilizado con un alcance distinto. Es evidente que la descentralización no implica sólo una modificación en el esquema de división funcional del trabajo entre jurisdicciones estatales. También afecta la dinámica política global del país, el rol de los partidos en el territorio y los intereses de los actores nacionales y locales.

Además, una transferencia con el alcance indicado contrariaría uno de los fundamentos básicos del Estado uruguayo y afectaría el fuerte centralismo que ha caracterizado la vida institucional del país. Por lo tanto, resulta difícil esperar que, de manera unilateral y voluntaria, el gobierno central se desprenda de aquellos atributos que han constituido la base de su poder durante más de un siglo. Es por eso, tal vez, que frente a los costos de transacción que supone persistir en este exacerbado centralismo, el Estado nacional haya optado por desconcentrar su aparato institucional y su gestión en el territorio.

La desconcentración, además, implica el traslado de una parte de las responsabilidades que antes se ejercían de manera excluyente desde Montevideo, a unidades organizativas localizadas en los departamentos. Si bien desconocemos la posible existencia de estudios que hayan analizado la 
conveniencia económica o técnica de producir esta localización territorial de la gestión estatal, es posible imaginar algunas de sus ventajas y desventajas.

Algunas pueden expresarse en términos presupuestarios, como por ejemplo, el costo relativo de mantener en forma permanente tales unidades territoriales y su personal, frente al de enviar periódicamente, desde Montevideo, a funcionarios que en forma itinerante y discontinua desempeñan ciertas funciones que exigen una presencia en la localidad. Otras son más cualitativas, como la posibilidad de que la existencia de unidades permanentes en el territorio y el contacto más próximo y cotidiano con la problemática departamental, permitan una traducción más ajustada de las políticas nacionales a la realidad local.

Algunos observadores estiman que el tamaño del país no justifica avanzar en la dirección de un proceso de descentralización, aún cuando admiten que el exceso de centralización es igualmente inconveniente. Uruguay es un país unitario, con altísima concentración del poder económico, político, social e intelectual en Montevideo, donde reside casi el 70\% de la población en la zona aledaña. Es casi inevitablemente y muy a su pesar, un país centralizado. Además, según la Constitución Nacional, la naturaleza de las intendencias no difiere demasiado de la de un típico municipio y se halla muy lejos de ser la principal unidad política responsable de la gestión pública en el nivel territorial, como es el caso de los estados o provincias en los países federales. Ello es así, aún cuando se haya decidido crear, con las alcaldías, el tercer nivel de gobierno ${ }^{3}$.

Por otra parte, si bien ciertas funciones podrían ser transferidas a las intendencias -o, al menos, éstas podrían tener un mayor protagonismo en su ejecución-, otras, siempre según las opiniones recogidas, sólo deben continuar a cargo del gobierno central (v.g., las educativas y las relacionadas con la salud). En esta interpretación, las intendencias deben tener funciones no muy diferentes a las de un típico gobierno municipal. Tal vez esta razón explique las dificultades que enfrenta la descentralización desde el segundo al tercer nivel de gobierno, recientemente creado, ya que no existe una nítida diferenciación de sus respectivas funciones ni se han definido criterios para establecerla. Claramente, las políticas nacionales no favorecieron posibles cambios en este rol, en tanto alentaron un desarrollo institucional del Estado orientado hacia la desconcentración y no hacia la descentralización.

3. En septiembre de 2009, el Parlamento uruguayo aprobó el proyecto de ley de Descentralización Politica y Participación Ciudadana que habilita la creación de unas 120 alcaldias en todo el país. Se creó así un tercer nivel de administración, más local, configurado por los centros poblados y sus áreas adyacentes. La ley dispone una descentralización política y administrativa. 
Un caso típico, al respecto, ha sido la reforma institucional del sistema de salud, ya que no consideró la posibilidad de descentralización como premisa de ese proceso de cambio. Las importantes políticas adoptadas en este campo tendieron a desconcentrar y mejorar la articulación funcional y jurisdiccional entre las instituciones nacionales, y entre éstas y las instituciones departamentales, sin resignar la capacidad de decisión centralizada, el desempeño de las funciones o el control de los recursos por parte del gobierno nacional. Una descentralización hubiera implicado transferir a los departamentos, la totalidad o buena parte del aparato institucional de implementación de las políticas, así como las fuentes de recursos para su atención.

Es interesante señalar que al desconcentrar su gestión -al menos en el campo de la salud-el gobierno nacional haya preferido llamarla "descentralización". Así, por ejemplo, cuando en el Ministerio de Salud Pública (MSP) se creó una unidad coordinadora de las direcciones departamentales de salud, la norma de creación la denominó Unidad de Descentralización Territorial. Tal vez ello se deba a que parece ser mucho más importante reducir el excesivo centralismo del Estado nacional que incrementar la participación de las intendencias en la gestión. Así, descentralizar equivale a des-centrar, a acercar la gestión al lugar donde la acción estatal debe producir resultados. De hecho, al analizar la norma que crea la Unidad de Descentralización Territorial del MSP, se observa que solo en una oportunidad se alude a la posible intervención de los gobiernos departamentales en la gestión de la salud, al señalar que una de sus funciones es generar políticas y herramientas de articulación intersectorial e interinstitucional en el ámbito departamental. Articulando la ejecución de políticas sociales y particularmente interactuando con Administración de los Servicios de Salud del Estado (ASSE), las intendencias y otras instituciones públicas en el desarrollo de acciones concretas de promoción y atención a la salud.

Como se observa, la norma admite la posibilidad de encarar acciones conjuntas con las intendencias, además de varias otras instituciones, pero sin reconocerles un protagonismo en su ejecución. De todos modos, también cabe suponer que al adoptar esta orientación, el gobierno también pudo haber considerado que una descentralización importante aumentaría las diferencias entre departamentos, por su disímil capacidad institucional para desempeñar las nuevas funciones que eventualmente les fueran transferidas. Según las opiniones recogidas, en algunas áreas funcionales estas diferencias podrían ser muy significativas, lo cual podría resentir la prestación de ciertos servicios en aquellos departamentos que acusan mayores déficit en su capacidad de gestión. 
Si la política actual es tratar de que el gobierno nacional esté más cerca del territorio, como reiteradamente ha sido planteado por el Presidente Mujica, cabe preguntar por qué no lo estaba antes de que esta orientación se abriera paso en la gestión de las políticas gubernamentales. Al respecto, el actual director de la Unidad de Descentralización Territorial del MSP, Dr. Pazos, señaló que al asumir la Presidencia el Dr. Tabaré Vázquez, el gobierno departamental de Montevideo era responsable de la prestación de la mayoría de los servicios, casi sin intervención del gobierno nacional. Por otra parte, según el ministro Olesker, el punto de partida en 2005 resultaba bastante desfavorable en términos de las posibilidades reales para alcanzar resultados efectivos en materia de descentralización. Por lo tanto, el primer gobierno del Frente Amplio decidió marcar el rumbo estratégico y comenzar a dar los primeros pasos en tal sentido. Los avances resultaron bastante disparejos, si se tienen en cuenta los intentos realizados por los distintos organismos, tanto desde el punto de vista de las propuestas efectivas en la materia, como de la adecuación o construcción de la estructura institucional que debía soportarlas.

Sin duda, la orientación impresa a este proceso consistió en la creación de una densa institucionalidad, destinada a fortalecer el proceso de articulación intra e interinstitucional de los organismos nacionales que operaban en el territorio. Al parecer, fue en el Ministerio de Desarrollo Social (MIDES) y el MSP donde se produjeron los mayores avances en términos de soporte institucional y desarrollo de políticas en el territorio. Ambos representan, según la opinión del ministro Daniel Olesker, "la mayor innovación para organismos con responsabilidades de rectoría de sus sectores en la política pública"s ${ }^{4}$.

Según el mismo informante, "el énfasis de la actual administración es congruente con el rumbo estratégico, además de convergente en el sentido de trabajar sobre una de las condiciones principales (desconcentración) que permite aproximarse al objetivo más ambicioso de la descentralización (desde la gestión y desde la transferencia de poder efectivo)". Es interesante señalar, no obstante, que si bien de la lectura de este juicio parecería deducirse que la desconcentración es un paso obligado en el proceso de descentralización. En tal sentido coincidiría con nuestra interpretación, 
otras manifestaciones del funcionario dejan pocas dudas de que el gobierno nacional nunca resignaría sus responsabilidades de prestación directa de los servicios (al menos en las áreas de salud y desarrollo social), sin perjuicio de asignar a las intendencias un rol de soporte y complementación en la prestación de tales servicios. Por ahora, la prioridad política parece centrada en la búsqueda de mejor articulación a través de la creación de mayor institucionalidad.

\section{LA INSTITUCIONALIZACIÓN ES UN PRERREQUISITO DE LA ARTICULACIÓN}

Según el ministro Olesker, en la medida de que el enfoque estratégico adoptado por el gobierno implique que la esfera de lo "territorial" no se encuentre subordinada a la esfera de la política nacional o central, la articulación resulta un instrumento sustancial para la descentralización. La articulación de políticas exige un fuerte trabajo interinstitucional e intersectorial cuyos resultados inmediatos son la superación de la fragmentación y la elaboración de políticas en el marco de estrategias de desarrollo colaborativas, acordadas con fuerte respaldo y legitimidad política. También permite una mayor racionalidad en el uso de los recursos humanos y materiales y, por ende, mayor eficiencia en la implementación de las políticas públicas, al multiplicar el resultado de los esfuerzos, no sólo sumarlos.

En ese sentido, la formalización de las Mesas Interinstitucionales de Políticas Sociales (MIPS), mediante un decreto impulsado desde el MIDES, constituye una de las herramientas de coordinación capaces de potenciar el producto, más que la simple sumatoria de esfuerzos. Una herramienta clave desde el punto de vista territorial, que exige que todos los ministerios del área social (a los que se suman los organismos de la educación, la salud y el Instituto del Niño y Adolescente del Uruguay (INAU), así como los gobiernos departamentales y otros ministerios ajenos al área social, como ganadería o defensa) definan de manera conjunta un plan de acción social en el territorio que, partiendo de una política social en el nivel nacional, priorice su aplicación específica en nivel departamental.

Sin lugar a dudas, el MIDES es la principal instancia institucional para la articulación y coordinación de la políticas sociales, tal como lo establece su ley orgánica, que además dispone la creación del gabinete social que el MIDES preside. Desde sus inicios (en 2005) el MIDES ha procurado avanzar en la articulación territorial de las políticas sociales. A la fecha, los avances han sido notorios, tal como surge de la consolidación de 32 
Oficinas Territoriales (OTEs), lo cual asegura la presencia del ministerio en todas las ciudades capitales del interior del país, en las tres macro regiones de Montevideo y Canelones y en ciudades importantes del interior (Bella Unión, San Carlos, Chuy, Río Branco, Dolores y Paso de los Toros). Adicionalmente, a través de la Dirección de Infamilia, el ministerio cuenta con 73 Servicios de Orientación, Consulta y Articulación Territorial (SOCAT) que permiten reforzar el despliegue territorial a nivel de micro territorios (barrios o localidades). Asimismo, a nivel de cada OTE se han conformado las Unidades Técnicas Territoriales (UTT) integradas por todos los referentes de direcciones e institutos del MIDES con acciones o programas en los territorios, lo que viene dotando de una mayor unidad de acción al ministerio en cada departamento o región.

Todo ello se vio acompañado por el fortalecimiento de la coordinación interinstitucional a nivel territorial mediante ${ }^{5}$ :

- Mesas Interinstitucionales de Políticas Sociales (MIPS), como ámbito de articulación y coordinación de las políticas sociales territoriales, convocado por el MIDES para desarrollar a nivel departamental los lineamientos establecidos por el Gabinete Social y por el CNCPS, que fundamentalmente toma en cuenta las prioridades a nivel de cada departamento. Están integradas por representantes de los organismos nacionales y los gobiernos municipales. Sus funciones incluyen: i) elaborar un inventario de las políticas sociales en el departamento, ii) elaborar la Agenda Social Departamental con las prioridades a nivel local y un cronograma de actividades, donde se determinan las acciones a llevar adelante, las medidas de gestión, los plazos, los productos esperados, así como las prioridades, iii) interactuar con organizaciones de la sociedad civil y con otras mesas de forma de poder prestarse mutuo apoyo y de coordinar acciones conjuntas.

- Consejos Sociales (CS). Son espacios para la construcción de la agenda social departamental así como la observación, el análisis y la elaboración de recomendaciones sobre las políticas públicas sociales desarrolladas en el nivel territorial. Están integrados por actores sociales departamentales de diverso grado de organización y áreas de trabajo, con capacidad para proponer, aportar y acompañar las políticas públicas. El MIDES, en su rol de promoción y construcción de estos espacios, promueve su desarrollo y fortalecimiento, facilitando el intercambio con la esfera estatal (Mesas Interinstitucionales) con relación a las políticas públicas implementadas en el nivel local. 
- Mesas de Coordinación Zonal (MCZ). Son espacios de participación comunitaria a nivel micro-territorial, impulsados desde los SOCAT e integrados por diferentes actores provenientes, tanto del ámbito institucional (público o comunitario) como particular (vecinos). El colectivo integrado en las MCZ identifica los principales problemas de la comunidad, dando prioridad a aquellos relativos a la infancia y la adolescencia a nivel local, y elabora diagnósticos, con los cuales se diseñan e implementan proyectos que proponen soluciones a los problemas detectados. Las MCZ (en caso de existir más de una en la región) participan junto a otros espacios de coordinación (Nodos Temáticos, Redes Locales, o Mesas Interinstitucionales Departamentales) en la construcción colectiva de un Plan Territorial para la infancia y adolescencia.

- Nodo Temático (NT). Es un dispositivo intersectorial que opera en el micro-territorio como una instancia que agrupa actores (operadores de instituciones y/o técnicos) para trabajar en torno a temas, casos y problemáticas específicas a nivel familiar y/o comunitario, con el propósito de realizar acciones focalizadas de atención, derivación y seguimiento.

Como puede observarse, las intendencias tienen reservadas algunas intervenciones en estas instancias de coordinación de políticas, aún cuando su rol no sea protagónico y, seguramente, varíe de departamento en departamento. Las intendencias y sus funcionarios tienen allí oportunidad de plantear su particular visión de la problemática local, así como sus objetivos y prioridades en materia de formulación e implementación de políticas, pero no asumen una responsabilidad directa en la gestión. Más bien, recogen y expresan las necesidades y demandas de la población departamental y desempeñan diversas funciones de suministro de instalaciones, bienes y servicios en las diversas áreas de gestión en las que participan.

En general, según afirman nuestros entrevistados, no hay de parte de las intendencias una demanda para asumir mayores responsabilidades de gestión. Procuran, por lo general, incrementar las transferencias de recursos para realizar obras o prestar servicios propios de sus competencias, aún cuando algunos intendentes son verdaderos protagonistas y tienden a asumir mayores compromisos. Como lo expresó gráficamente un funcionario nacional, "el gobierno departamental se cobija bajo el gran paraguas de las políticas nacionales". 
Por otra parte, para avanzar hacia una descentralización efectiva, el componente de participación popular adquiere una importancia fundamental, en particular para que el diálogo entre las esferas territorial, sectorial y política resulte efectivo. Cuando se plantea la participación desde esta mirada, surge la posibilidad de una sistemática retroalimentación que permita formular o rediseñar la institucionalidad del sector público, y no solamente una nueva forma de relación entre el Estado y la sociedad.

La participación, según la opinión generalizada de nuestros interlocutores, debe promover la intervención de la ciudadanía en la definición, gestión, monitoreo y evaluación de las políticas, programas y proyectos planteados desde el gobierno central. La retroalimentación de la ciudadanía debe permitir que se efectúen modificaciones a estas acciones o cambios de énfasis, en función de las distintas realidades que muestra el territorio, sin que por ello el gobierno nacional pierda su capacidad como rector de las políticas.

Fue precisamente este convencimiento el que condujo a que, durante el gobierno del Dr. Tabaré Vázquez, el Ministerio de Salud Pública advirtiera que no estaba cumpliendo el papel de rectoría en este campo. No ejercía adecuadamente su rol de regulación, de fiscalización ni de formación de recursos humanos. Se decidió entonces, fortalecer estos roles propios de una función rectora, dejando de prestar directamente los servicios de salud pública y asignando esta responsabilidad a la Administración de los Servicios de Salud del Estado (ASSE), que ya existía como dependencia del Ministerio, convirtiéndolo en un organismo descentralizado con presupuesto propio, bajo la tutela ministerial.

Por otra parte, a los efectos de articular las políticas de salud en el territorio, se crearon -durante la gestión del Ministro Olesker- 19 direcciones departamentales, de modo de asumir plenamente la mencionada función de rectoría en materia de fiscalización o de vigilancia epidemiológica, que casi no se desarrollaba. También se creó la Unidad de Descentralización Territorial a cargo de la coordinación de todas las oficinas departamentales, que actúan como interfase entre las necesidades locales y las políticas fijadas en el nivel nacional. Uno de sus logros ha sido que la discusión de las políticas se realice en el territorio, reuniendo periódicamente a los directores departamentales en una determinada localidad.

Esta desconcentración territorial se llevó a cabo con muy escasos recursos, pero al menos se consiguió que tanto las unidades departamentales creadas como los cargos de directores y su respectiva asignación presupuestaria, fueran incluidos en la Ley de Presupuesto, al igual que la unidad y el cargo 
del Director de la Unidad de Descentralización. Al margen de reflejar un claro cambio de orientación política, estas decisiones, en la medida que hicieron posible un flujo asegurado de recursos, le otorgaron a la política de desconcentración mucha mayor continuidad, poniéndola a salvo de los avatares y la frecuente rotación de funcionarios políticos en los cargos jerárquicos. Después de todo, como afirmara el responsable de la Unidad de Descentralización del MSP, "las políticas de Estado son aquellas que consiguen ser presupuestadas"

Entre las ventajas que produjeron la desconcentración y mayor articulación de la labor ministerial, se consiguió que los coordinadores departamentales realizaran diagnósticos de la situación de la salud en la localidad, tareas de prevención y vigilancia, de promoción y fiscalización, entre otras. Además, se consiguió radicar físicamente a los directores en el territorio y dotarlos de un elenco estable de colaboradores, que en promedio alcanza a las siete $\mathrm{u}$ ocho personas por sede. Si bien su nivel técnico no es óptimo, se han hecho esfuerzos por capacitar a ese personal, tanto en el nivel central como territorial.

En ciertos casos, se ha conseguido trabajar en forma conjunta y colaborativa con la Intendencia; en otros casos, en conflicto con la misma. Pero como observara el Ministro Olesker, en la medida en que se logre mayor claridad y especialización en la responsabilidad de los distintos niveles de gobierno, pueden alcanzarse grados de colaboración importantes entre ambas instancias, aún cuando no haya siempre coincidencia en los respectivos signos político-partidarios. Sobre todo, en torno a las cuestiones políticas más críticas, como la seguridad, la educación, la energía y el medio ambiente, en las que el país durante el gobierno actual, ha planteado la necesidad de concretar acuerdos nacionales, sobre todo, en materia de prioridades territoriales.

Según ha podido reconstruirse, la creación de instancias institucionales como las Juntas Departamentales de Salud, permitió iniciar un diálogo amplio alrededor del tema de la articulación de políticas en el territorio. Originariamente, el proyecto del Presidente Mujica era crear la figura del Coordinador Departamental, especie de delegado del Poder Ejecutivo en cada jurisdicción subnacional, para que asumiera esa función coordinadora, pero la cerrada oposición de los intendentes y de otras fuerzas políticas a esta iniciativa, determinó su abandono. Otro proyecto consistió en

6. Para marcar un contraste entre el Departamento de Montevideo y el resto de los gobiernos departamentales, para cumplir las mismas funciones en el territorio, el gobierno de la capital requeriría unas 80 personas. En la actualidad, estas funciones las cumple el MSP y si bien existe un Director Departamental, no existe en Montevideo una unidad equivalente a la de los demás departamentos. 
la creación de Coordinadores Regionales, figura que -según opiniones recogidas- solo sería aceptable para los intendentes si los mismos no se convierten en competidores políticos de los mismos.

Estos antecedentes permiten concluir que i) la coordinación y articulación de políticas en el territorio constituye una prioridad insoslayable para el gobierno nacional; y ii) que no es posible lograrlo sin alcanzar un aceptable grado de consenso y participación por parte de los intendentes. En las palabras de un entrevistado, refiriéndose a un área particular de la gestión, "no hay política social en el territorio sin los intendentes, que son quienes tienen el vínculo directo con la gente, por lo cual el gobierno nacional está obligado a articular con las intendencias".

La participación de los gobiernos departamentales en los nuevos esquemas institucionales creados para mejorar la coordinación de políticas se produce a través de diferentes mecanismos. Por ejemplo, el Gabinete Social lo integran los ministros de Educación, Salud, Trabajo, Desarrollo Social, Turismo y Deporte, Vivienda, Obras Públicas y Economía y Finanzas. Pero dependiendo directamente del mismo, el Consejo de Política Social, que aplica la línea política del gabinete social, lo integra junto a todos los servicios descentralizados del área social (v.g., de MSP, ASSE, cultura), el Congreso de Intendentes.

Las Mesas Intersectoriales en el nivel departamental constituyen otra instancia en las que también participan representantes de las intendencias. Al parecer, su desempeño es más controvertido (se registran opiniones favorables y desfavorables respecto a su efectividad), pero ello se debe fundamentalmente al carácter vertical y sectorial de las políticas de cada una de las áreas intervinientes y la falta de transversalidad, lo cual incrementa la complejidad y dificultad de sus deliberaciones y acuerdos. Por último, en agosto de 2011, se oficializaron por decreto las Mesas Interinstitucionales de Políticas Sociales, como espacios de intercambio, articulación y coordinación de las políticas, planes y programas sociales a nivel territorial, que integran prácticamente a todos los ministerios del gobierno nacional y han elaborado agendas estratégicas departamentales.

\section{L A D E S C E N T R A L I Z A C I ÓN C OMO H I P Ó T E S I S}

A lo largo de nuestra investigación hemos tratado de hallar indicios que permitan sostener la hipótesis que, en algún momento y con relación 
a determinadas áreas de la gestión pública, el gobierno nacional decida adoptar una política de descentralización hacia los gobiernos subnacionales. No hemos encontrado tales indicios y todo parece indicar que, por el contrario, el gobierno central se encamina a reforzar su presencia territorial, sin resignar poder, recursos ni responsabilidades de gestión. Tampoco existe una demanda social para que se produzcan tales transferencias ni, salvo posibles excepciones, una clara vocación de los departamentos por hacerse cargo de mayores cometidos.

Sin embargo, no sería un ejercicio ocioso plantear un escenario institucional futuro, en el que podrían imaginarse avances en dirección hacia un proceso de descentralización. Para ello, y más allá de la obvia voluntad política requerida de parte del Estado nacional para adoptar este modelo de gestión, sería necesaria la convergencia de una serie de condiciones. En primer lugar, debería existir un alto grado de consenso en que la descentralización puede conducir a que el conjunto de la actividad estatal genere mayor valor público, es decir, satisfaga con mayor eficiencia y calidad las necesidades y demandas de la ciudadanía. Por cierto, ello dependería en parte de una ecuación económica en la que deberían computarse, entre otras cosas, los costos relativos de producir bienes y servicios públicos en uno $\mathrm{u}$ otro nivel jurisdiccional, tanto los de producción directa como los requeridos por las funciones de dirección política, planificación, seguimiento, control de gestión y evaluación de resultados.

En parte, también, ciertas competencias del gobierno nacional tienen un carácter indelegable, como las relaciones exteriores, la justicia, la defensa o la seguridad. En otros casos, resulta justificable reservar para el Estado nacional un papel preponderante en la rectoría de las políticas sectoriales y en la responsabilidad de la prestación básica de servicios (como en educación, salud, desarrollo social, turismo o infraestructura), sin perjuicio de que las intendencias participen de los procesos de elaboración de políticas o complementen de variadas formas, la prestación de los servicios. Como señalara un entrevistado, "no resulta justificable que el gobierno nacional abandone una mirada central en el proceso de iniciación e implantación de las políticas (sociales), velando así por la justicia territorial, ya que se corre el riesgo de que cada localidad sobre-represente a su población en los beneficios de una política, sea quien fuere quien gobierne".

Otra consideración importante para justificar la decisión de descentralizar es que en el área de política en que se plantee esta opción, la ciudadanía esté en condiciones de ejercer un mejor control de la gestión pública o de participar en la cogestión de las respectivas políticas. En los hechos, la participación ciudadana se manifiesta i) en los procesos de formación de 
las políticas públicas, ii) en la ejecución de las respectivas decisiones y iii) en la evaluación o control de la gestión pública. Es decir, en los tres tiempos -futuro, presente y pasado- en que se programa, desenvuelve y evalúa toda actividad institucional.

Así, acuerdos público-privados pueden influir en la creación de los escenarios políticos futuros que debe decidir una sociedad para alcanzar un modo de organización social deseable; la co-producción cotidiana y rutinaria de bienes y servicios, complementando o suplantando al Estado o al mercado, puede constituirse en una actividad recreada en cada presente; o el seguimiento permanente de las políticas, el control de la gestión y la evaluación de los resultados conseguidos por las instituciones estatales privilegian el pasado como dimensión temporal significativa. Posiblemente, dentro de su limitada importancia, los mayores avances producidos en la participación ciudadana durante los últimos años, han tenido lugar en los planos de la construcción del futuro y de la revisión del pasado de la gestión gubernamental, ya que su rol co-productor o co-gestor de servicios ha sido muy reducido. Pero aún si este fuera un rol activo, existiría todavía un abismo entre la calidad de esa gestión pública y el papel que puede cumplir la sociedad civil en su mejoramiento.

La demanda generada desde el propio nivel subnacional también puede constituir un argumento de peso para decidir avances hacia una mayor descentralización. La ausencia actual de presiones, en tal sentido, no constituye necesariamente una traba para tal avance. Lo importante es considerar qué aspectos de la gestión son posibles de ser descentralizados. Bajo cualquier hipótesis, el Estado nacional deberá retener ciertas responsabilidades de dirección política, planificación global, regulación, evaluación y control de gestión. Según manifestaciones del Ministro Olesker: "En materia de políticas sociales, la transferencia de cometidos a los gobiernos departamentales no aparece como lo más aconsejable. Las reformas de salud y de educación -dos componentes centrales de la estructura de la reforma social- deben retener la responsabilidad nacional en su regulación; las experiencias de departamentalización en estas áreas a nivel internacional no han sido buenas. La visión global (debe aportarla) el gobierno nacional".

Y agrega, al respecto:

“Cuál es el real sentido de que un gobierno departamental desarrolle un programa de centros de atención a la primera infancia gestionado, supervisado y financiado por el propio 
gobierno departamental que convive en simultáneo con la oferta pública (Plan CAIF), y que a la vez el gobierno central transfiera recursos financieros a dicho gobierno departamental, parte de los cuales quizás sean utilizados para el financiamiento de los mencionados centros. Así podríamos seguir; esto no obsta a que algunos cometidos complementarios de implementación, puedan trasladarse a las intendencias, dada su cercanía con los territorios".

En parte, descentralizar depende asimismo del carácter especializado de la actividad. Por ejemplo, el Dr. Fernández Galeano, señala con respecto al campo de la salud, que podrían considerarse dos modelos. Uno consistiría en la lisa y llana descentralización, solución que a su juicio es altamente inconveniente. Más aún, considera que sería un error otorgarle competencias de atención de la salud a las intendencias. Los costos de transacción serían demasiado altos, dada la naturaleza altamente especializada de estos servicios. Las intendencias -en su opinión- deberían concentrar sus competencias en la prestación de los servicios urbanos tradicionales. Según el otro modelo, es acertado que ASSE sea la prestadora de la atención de salud, pero admite la necesidad de que se articulen recursos con una visión interestatal y una colaboración público-privada. No cree que las intendencias puedan asumir la responsabilidad de atender el primer nivel de atención ${ }^{7}$ Podrían, en cambio, complementar el servicio a través de lo que denomina "concurrencia de competencias".

Existen, naturalmente, otros modelos posibles, aunque todos ellos descansan sobre la precariedad de acuerdos y recursos relativamente efímeros. Nuestros entrevistados citaron como opciones adecuadas, la gestión asociada para planes territoriales concretos, como los proyectos derivados de la estrategia Uruguay Integra de OPP o el exitoso proyecto "Canelones Crece Contigo", donde la Intendencia creó un equipo que funciona en forma paralela a la estructura del gobierno departamental, en el que la responsabilidad de la gestión se halla a cargo de una Unidad Ejecutora del Programa de Naciones Unidas para el Desarrollo (PNUD). Lo importante, según el Dr. Pazos, es conseguir presupuesto por proyecto para

7. Una interesante experiencia, en tal sentido, ha sido la del Proyecto Red de Nodos de Salud Barriales y Zonales, en el que confluyeron diversos socios (Ministerios de Salud Pública y de Desarrollo Social, Facultad de Medicina de la Universidad de la República, ASSE y otros), proyecto que contó con financiamiento de la Unión Europea. Pero nuestros entrevistados coincidieron en que, pese a su originalidad, sus bases institucionales han sido débiles y su sostenibilidad bastante precaria. Por otra parte, si bien las intendencias han participado de estas redes, su papel ha sido relativamente reducido. 
ir convirtiendo este tipo de iniciativas en objeto de una política nacional permanente. Se seguiría así el modelo de otro proyecto exitoso, como es el "Plan Ceibal" 8 .

En definitiva, la opinión mayoritaria se inclina por un modelo según el cual el gobierno nacional mantendría la responsabilidad primaria por la rectoría política y la prestación de servicios, tal cual lo viene haciendo actualmente. Pero se admite y se tiende a considerar conveniente que exista una participación activa de los departamentos y, ahora, de las alcaldías, en la provisión de infraestructura y en los procesos de planificación, seguimiento y control. Esta forma de participación permitiría optimizar los recursos disponibles en cada nivel de gobierno y reforzaría la especialización funcional de cada actor gubernamental.

\section{LA D ESCONCENTRACIÓNCOMO \\ AVANCE HACIA LA DESCENTRALIZACIÓN}

Uno de los factores que suele plantearse como condición necesaria para llevar a cabo un proceso de descentralización, es la existencia de una capacidad de gestión local suficiente como para asumir las responsabilidades transferidas desde una instancia jurisdiccional de nivel superior. Esta capacidad supone, en primer lugar, el acceso a fuentes de recursos previsibles y estables, que permitan atender el financiamiento de los servicios objeto de la transferencia. Que los gobiernos locales puedan contar con estos recursos depende, entre otras posibilidades, de que el gobierno nacional disponga la transferencia de los fondos desde el tesoro nacional a los gobiernos locales con un carácter permanente, co-partícipe con estos impuestos administrados centralmente o renuncie a una determinada fuente, permitiendo el uso de la potestad fiscal por parte de las jurisdicciones subnacionales. También podría ocurrir que el gobierno nacional decida retener la capacidad recaudatoria y, simplemente, transfiera los recursos a los gobiernos subnacionales para atender los servicios localmente.

8. El Plan Ceibal busca promover la inclusión con el fin de disminuir la brecha digital tanto respecto a otros países, como entre los ciudadanos de Uruguay, de manera de posibilitar un mayor y mejor acceso a la educación y a la cultura. Su manifestación más conocida ha sido la entrega gratuita a cada alumno y a cada maestro, de una computadora portátil. 
Sea como fuere, una vez asegurada la fuente de recursos, la siguiente condición de la descentralización es la existencia de capacidad local para asegurar la eficaz prestación de los servicios. Ello supone, en primer lugar, la disponibilidad de un elenco de funcionarios con la formación y experiencia necesarias para asumir tales responsabilidades. Podría señalarse al respecto que, casi con seguridad, buena parte de esa capacidad existiría bajo cualquier hipótesis, en la medida en que la descentralización implica generalmente transferir de una jurisdicción a otra, servicios que ya se están prestando en el territorio. En principio, sólo cambiaría entonces la personería jurídica del responsable de esos servicios ${ }^{9}$.

Sin embargo, tal capacidad no incluiría las requeridas por el ejercicio de una gran variedad de funciones, particularmente las de dirección política, regulación, fiscalización, capacitación laboral, informática, negociación salarial, entre otras. Cuando estas funciones no son desconcentradas hacia el territorio, suelen desempeñarse desde el gobierno nacional en forma centralizada. Por ejemplo, mediante el envío periódico a las localidades de inspectores, supervisores, capacitadores, negociadores u otros funcionarios responsables de dichas gestiones. En estos casos, la capacidad de gestión no se transfiere a los gobiernos departamentales ni queda siquiera localizada en el territorio, con lo cual una posible descentralización debería enfrentar el desafío de crearla ex novo. Al respecto, el director departamental del MSP señalaba en una entrevista que una de las políticas de desconcentración del ministerio es fortalecer las funciones de regulación y fiscalización desde los centros departamentales del ministerio, reduciendo así la dependencia de personal enviado desde Montevideo. Entre otras cosas, ello requiere desagregar -en términos que consulten las realidades locales- la normativa que hoy se aplica desde el gobierno central.

En cambio, si el gobierno nacional inicia una política de desconcentración tendiente a instalar en el territorio la responsabilidad de esos otros servicios de apoyo -indirectamente relacionados con la prestación final a

9. Vale la pena hacer hincapié en este punto. No hay descentralización sin la previa existencia en el territorio de organismos dependientes de un nivel jurisdiccional mayor, que vienen produciendo bienes o prestando servicios localmente desde antes. Casi nunca requiere desplazamiento físico de bienes o personas. Inclusive, desde el punto de vista estrictamente operativo, la descentralización podría implicar muy pocos cambios, ya que la actividad continuaría desarrollándose con el mismo personal e infraestructura y sólo daría lugar a una modificación en su dependencia jurisdiccional. Aún en un pais federal, como Argentina, es interesante citar que antes de producirse la masiva privatización de empresas y la transferencia de servicios del gobierno nacional a las provincias, la cantidad de funcionarios públicos nacionales destacados en el interior del país, alcanzaba aproximadamente al 63\% de la dotación total del gobierno nacional (Oszlak, 1989). Es decir, el Estado nacional estaba radicado mayoritariamente en el interior y la descentralización se produjo en un tiempo extraordinariamente breve. 
los usuarios- termina radicando localmente tales capacidades, aún cuando no lo haga mediante la transferencia formal de cometidos a la instancia departamental. A nuestro juicio, éste es un punto fundamental a tener en cuenta con respecto a una futura estrategia realmente descentralizadora.

La gran mayoría de nuestros entrevistados considera que no es razonable esperar la adopción de una estrategia semejante en el corto o mediano plazo. Evidentemente, la actual orientación del gobierno uruguayo es "llevar el Estado nacional al territorio", política que en principio iría en dirección contraria a la descentralización o, al menos, reforzaría la presencia territorial del gobierno central.

Sin embargo, la paulatina transferencia de responsabilidades a las unidades desconcentradas tendería a generar varias consecuencias. En primer lugar, como se ha dicho, tal orientación tiende a territorializar la capacidad de gestión del Estado. Los funcionarios nacionales suelen ser oriundos del departamento o se radican en el mismo, establecen sus familias y sus vinculaciones sociales, se compenetran cotidianamente de los problemas locales, crean redes de relaciones con otros funcionarios nacionales y departamentales, así como con organizaciones de la sociedad civil. Casi inevitablemente, adquieren una doble lealtad -funcional y jurisdiccional-, en su simultáneo rol de representantes del gobierno nacional en el territorio y de vecinos preocupados por el problema de la jurisdicción en que trabajan diariamente.

Además, el conocimiento pormenorizado de la problemática local que adquiere el funcionario nacional destacado en el departamento, le permite interpretar los pormenores de la problemática objeto de su intervención, e identificar -dentro del marco de las políticas nacionales del caso- los mecanismos más adecuados para el cumplimiento de su rol ${ }^{10}$. Por otra parte, la creación por los ministerios de unidades departamentales, ha abierto la posibilidad de un mayor intercambio entre sus responsables, entre sí y con las autoridades del gobierno central. Por ejemplo, como se ha señalado, los directores departamentales del MSP se reúnen mensualmente en Montevideo para analizar una agenda de problemas comunes y discutir posibles mecanismos para resolverlos. Este contacto horizontal contribuye aún más a que las políticas nacionales puedan evaluarse a la luz de la experiencia común de los responsables territoriales de aplicar tales políticas.

10. Según un representante de una de las instituciones firmantes del Convenio de Nodos de Salud, debería existir una mayor autonomía de los representantes locales de esos organismos centrales, para el desarrollo de actividades puntuales en el territorio. 
Asimismo, este conocimiento más inmediato y próximo a la localidad, abre la posibilidad de que el funcionario pueda retroalimentar el proceso de formulación de políticas globales que a veces fallan en la consideración de las realidades locales ${ }^{11}$. Este papel puede, a su vez, potenciarse a través del contacto del coordinador departamental con sus pares de otros departamentos, así como con representantes de unidades ejecutoras de otros incisos ${ }^{12}$, para el análisis conjunto de instrumentos de gestión más aptos para la implementación de las políticas en el nivel departamental. Si bien estos contactos son a veces difíciles, al chocar con resabios culturales enraizados y contradictorios o con búsquedas inevitables de protagonismo, constituyen potencialmente un mecanismo fundamental de acción concertada sobre problemáticas comunes.

Si el objetivo de la desconcentración es lograr una mejor articulación de la labor del gobierno nacional en el territorio, es casi inevitable que en este mismo proceso se potencie la posibilidad de producir articulaciones "verticales" con las instituciones departamentales, incluyendo tanto a las intendencias como al sector privado y a las organizaciones de la sociedad civil. Es natural que el contacto permanente y físicamente cercano con esas instituciones, abra oportunidades de análisis conjunto y trabajo colaborativo en torno a cuestiones de preocupación común. Esta posibilidad es más remota cuando los contactos no son frecuentes y no se crea, por lo tanto, la necesaria identificación compartida de los problemas y sus eventuales soluciones.

La apertura de estas oportunidades de colaboración podría conducir a que las intendencias vayan asumiendo algunas responsabilidades de gestión, en la medida en que la propia naturaleza de las actividades requeridas permita ir descubriendo las posibles ventajas comunes de su intervención. La experiencia de los Nodos de Salud en Tacuarembó es un caso típico que, si bien no se ajusta a un modelo de gestión descentralizada, tiene algunos ingredientes que lo ubican dentro de esa zona gris en que las intendencias se hacen cargo de una parte no despreciable de la gestión. En el caso de la gestión de la Atención Primaria de Salud (APS), mediante el aporte de personal, recursos materiales y, durante un cierto lapso, capacidad de administrar una unidad ejecutora de proyecto. El punto que se pretende destacar es que es esta conjunción de circunstancias la que posibilita la asunción de un

11. Varios entrevistados señalaron que las políticas públicas hechas en Montevideo no se ajustan a las realidades departamentales y, sobre todo, a las de las localidades. Más aún, la normativa no toma en cuenta la escala del nivel rural ni contempla especifidades locales dentro de esta población.

12. El término "inciso" se utiliza en Uruguay como equivalente de ministerio. 
rol más protagónico por parte de las intendencias. Esta conclusión avala el argumento -tal vez paradójico- de que la desconcentración en Uruguay es una vía posible hacia una creciente descentralización.

\section{ENFOQUE METO D O L Ó G I O PARA DECIDIR UNA DESCENTRALIZACIÓN}

El Estado nacional actual se halla sometido en todo el mundo a una doble $\mathrm{y}$, en apariencia, contradictoria exigencia. Por una parte, ha perdido parte de su capacidad de decisión autónoma, en la medida en que la internacionalización de los estados, la globalización y la integración regional reclaman un nuevo protagonismo a las instancias institucionales supranacionales. Por otra, debido a su mayor complejidad y a la demanda de las propias fuerzas sociales, se ve exigido a descentralizar su gestión hacia los niveles subnacionales.

Si bien esta tendencia no ha alcanzado en Uruguay un grado de importancia crucial, no puede descartarse que en algún momento el gobierno nacional decida avanzar en un proceso de real descentralización, sea porque han madurado las condiciones políticas para ello, porque se dispone en el nivel departamental de la capacidad técnica para asumir mayores responsabilidades o por alguna combinación de éstas u otras circunstancias. Es posible también que esa decisión coincida con una mayor demanda de las propias intendencias (y/o de la sociedad civil) por asumir mayor protagonismo en la gestión de políticas que hoy son resorte del gobierno nacional.

Si efectivamente se dieran esas circunstancias, no sería recomendable proceder a ciegas a través de la adopción de medidas de transferencia generalizada de las áreas de gestión centralizada a los departamentos. Este tipo de decisiones aceleradas y drásticas han tenido efectos altamente perjudiciales en algunas experiencias, como Argentina, donde la masiva descentralización de la salud y la educación hacia las provincias, en los años 90, generó enormes problemas de gestión que aún hoy no han sido resueltos.

Por ello proponemos un enfoque metodológico que reconstruye la secuencia lógica de razonamientos conducente a la adopción de una adecuada política de descentralización. Consideramos que este tipo de decisiones políticas exige un análisis profundo de diversas variables, que al menos debería incluir cuatro aspectos estrechamente relacionados entre sí: 
1. las áreas funcionales en que podría considerarse la posible transferencia de responsabilidades del gobierno nacional a los departamentos;

2. los procesos de gestión que, técnicamente, podrían ser asumidos por las intendencias y aquellos otros que debería retener el gobierno nacional;

3. la conveniencia de llevarla a cabo, según diversos criterios e indicadores; $\mathrm{y}$

4. las acciones de desarrollo institucional requeridas antes de proceder a descentralizar gestiones, según las áreas funcionales seleccionadas.

La metodología propuesta parte de una Matriz de Descentralización Prospectiva (MDP), en la que las dimensiones estarían conformadas, respectivamente, por las áreas funcionales y los procesos de gestión. En un primer análisis, en las celdas de la matriz se indicaría qué procesos de gestión admitirían, en principio, ser asumidos como responsabilidad de las intendencias, según los criterios e indicadores que se sugerirán más abajo, dependiendo de las áreas de gestión correspondientes. En un segundo análisis, en aquellos casos (celdas) en que resulta posible y conveniente la transferencia de cometidos, se procedería a analizar qué déficit de capacidad institucional deberían encararse y resolverse, antes de que una descentralización efectiva pudiera considerarse. Este procedimiento, que se ajusta a una estricta lógica, se plantea como posible ejercicio analítico para el caso de que la hipótesis que se viene considerando en esta sección llegara a concretarse. Veamos cómo funcionaría prácticamente.

ÁREAS FUNCIONALES. En el Cuadro 1 se enumera una serie de áreas funcionales que, potencialmente, podrían ser objeto de algún tipo de gestión por parte de un gobierno subnacional. Las denominaciones no designan necesariamente unidades organizativas formales, sino áreas o cuestiones que habitualmente forman parte de la agenda estatal, aún cuando en muchos casos ambas coincidan. Se han agrupado las áreas funcionales en tres categorías de cuestiones de mayor nivel de abstracción -gobernabilidad, desarrollo y equidad-, para efectos de un mejor ordenamiento.

Como la matriz está concebida para cruzar, en principio, áreas funcionales con procesos de gestión, se requiere que cada una de ellas sea desagregada, a su vez, ya que distintas gestiones realizadas en una determinada área podrían o no ser transferidas del gobierno central al departamental. Para ilustrar este punto, la gestión de políticas de salud pública incluye, habitualmente, funciones de definición de políticas, prevención y atención primaria, administración hospitalaria, habilitación de laboratorios, 
regulación de la salud, seguridad de medicamentos, etc. Algunas de estas subáreas admiten la intervención de las intendencias en su gestión, otras no. De ahí la necesidad de desagregación. Como no nos resulta posible ni tiene mayor sentido desagregar todas las áreas funcionales en esta matriz, hemos elegido como ilustración un par de ellas, a fin de que la metodología propuesta resulte más clara (ver Cuadro 2).

CUADRO 1: MATRIZ DE DESCENTRALIZACIÓN PROSPECTIVA ÁREAS FUNCIONALES DE DESARROLLO

\begin{tabular}{|c|c|c|c|c|c|c|c|c|c|c|}
\hline ÁREA FUNCIONAL & \multicolumn{10}{|c|}{ PROCESOS DE GESTIÓN } \\
\hline \multirow[b]{2}{*}{$\begin{array}{l}\text { Industria } \\
\text { y Comercio }\end{array}$} & 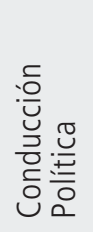 & 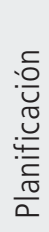 & 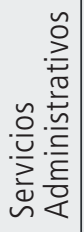 & 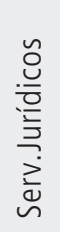 & 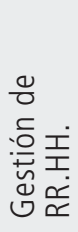 & 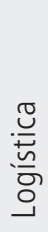 & 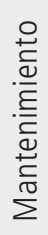 & 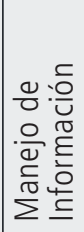 & 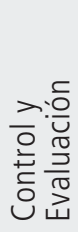 & 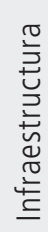 \\
\hline & & & & & & & & & & \\
\hline Turismo & & & & & & & & & & \\
\hline Minería & & & & & & & & & & \\
\hline Frutohorticultura & & & & & & & & & & \\
\hline $\begin{array}{l}\text { Agricultura y } \\
\text { Ganadería }\end{array}$ & & & & & & & & & & \\
\hline $\begin{array}{l}\text { Bosques, Fauna y } \\
\text { Parques Provinciales }\end{array}$ & & & & & & & & & & \\
\hline Tierras & & & & & & & & & & \\
\hline $\begin{array}{l}\text { Recursos } \\
\text { Hídricos }\end{array}$ & & & & & & & & & & \\
\hline Medio Ambiente & & & & & & & & & & \\
\hline
\end{tabular}


CUADRO 1: MATRIZ DE DESCENTRALIZACIÓN PROSPECTIVA

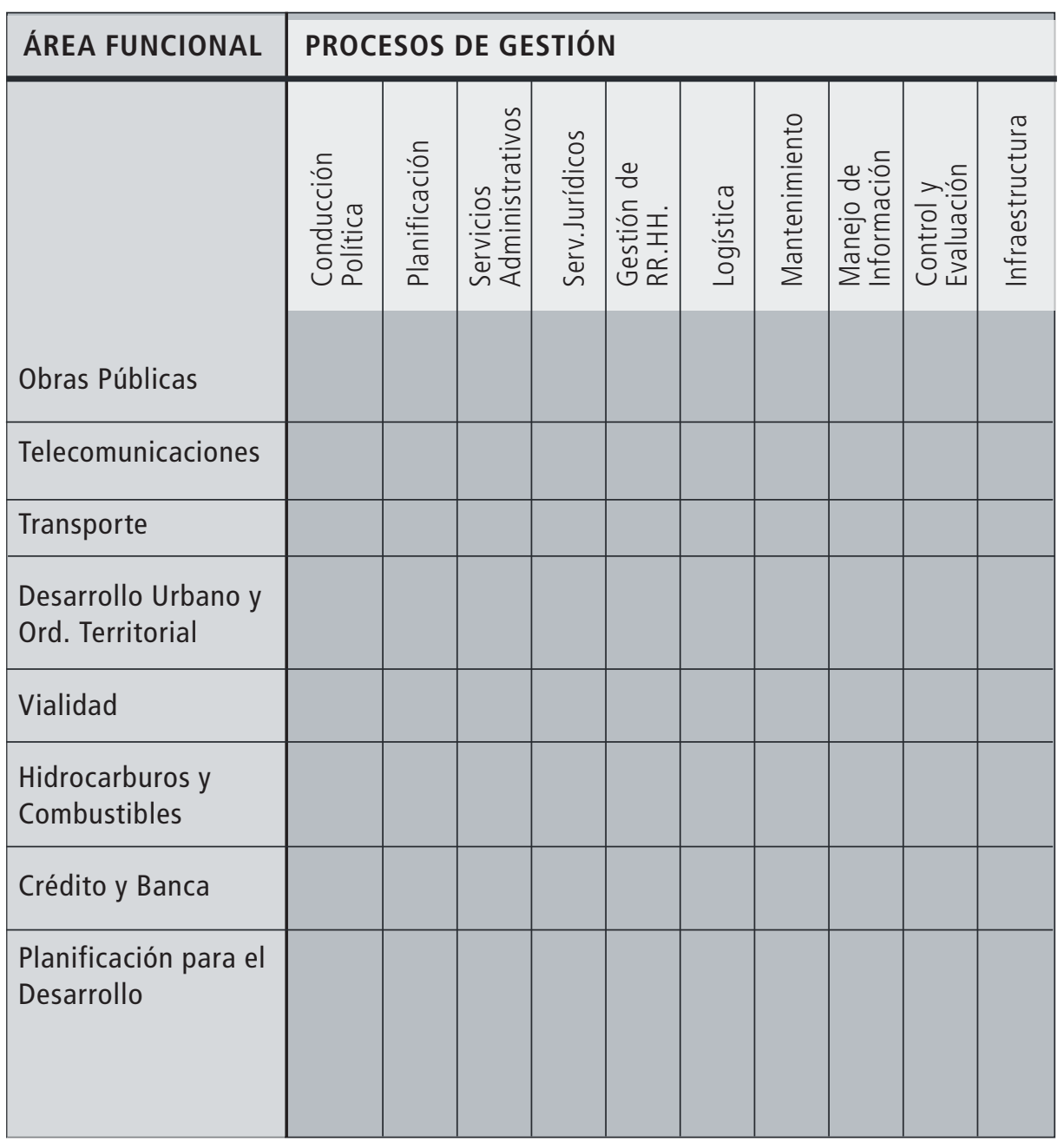


ÁreAs FunCIONALES DE DESARROLLO CUADRO 1: MATRIZ DE DESCENTRALIZACIÓN PROSPECTIVA ÁREAS FUNCIONALES DE EQUIDAD

\begin{tabular}{|c|c|c|c|c|c|c|c|c|c|c|}
\hline ÁREA FUNCIONAL & PROC & SOS & DE GE & TIÓ & & & & & & \\
\hline \multirow[b]{2}{*}{ Salud } & 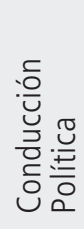 & 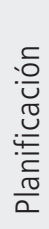 & 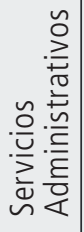 & 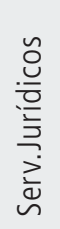 & 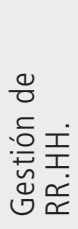 & 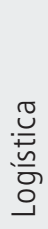 & 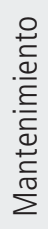 & 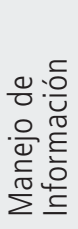 & 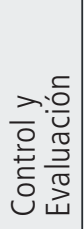 & 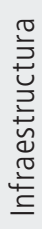 \\
\hline & & & & & & & & & & \\
\hline \multicolumn{11}{|l|}{ Educación } \\
\hline \multicolumn{11}{|l|}{ Acción Social } \\
\hline \multicolumn{11}{|l|}{ Seguridad Social } \\
\hline \multicolumn{11}{|l|}{ Familia } \\
\hline \multicolumn{11}{|l|}{ Juventud } \\
\hline \multicolumn{11}{|l|}{ Deportes } \\
\hline \multicolumn{11}{|l|}{ Cultura } \\
\hline \multicolumn{11}{|l|}{ Trabajo } \\
\hline \multicolumn{11}{|l|}{ Vivienda } \\
\hline Agua y Saneamiento & & & & & & & & & & \\
\hline
\end{tabular}


CUADRO 1: MATRIZ DE DESCENTRALIZACIÓN PROSPECTIVA ÁREAS FUNCIONALES DE GOBERNABILIDAD

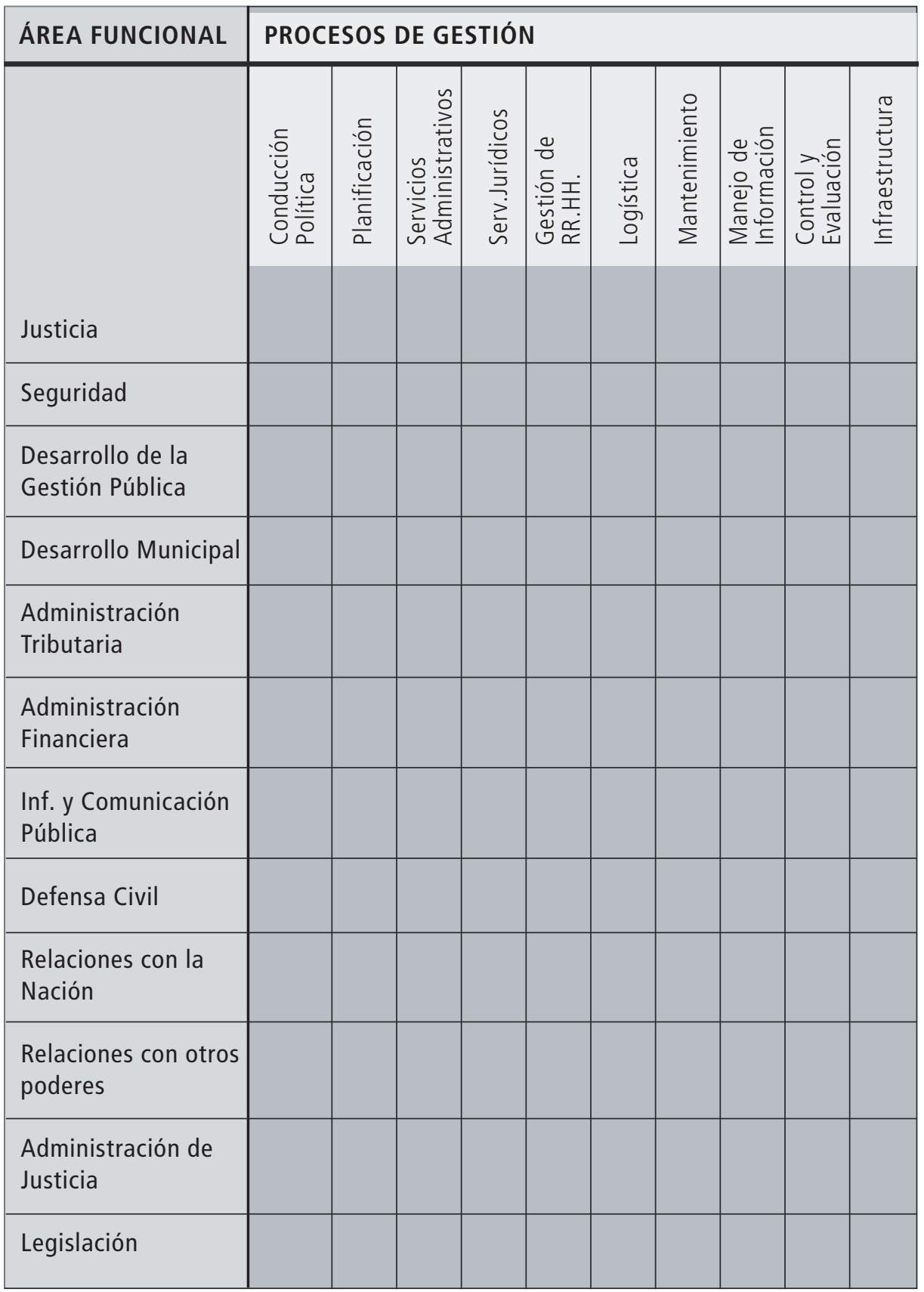


PROCESOS DE GESTIÓN. Denominamos procesos de gestión a los diferentes tipos de actividades que, en cada área funcional, pueden ser objeto de intervención por parte de una unidad organizativa (por ejemplo, de un gobierno), sea que esta responsabilidad consista en la producción de un bien, una actividad de regulación, la prestación de un servicio, así como en el control de estos resultados o en alguna otra forma de intervención en el proceso de producción de los mismos.

Las gestiones pueden ser sustantivas, relacionadas con los productos o resultados que justifican la existencia del organismo responsable de su producción o prestación; o de apoyo, consistentes en la realización de tareas que permiten obtener y asignar los insumos necesarios para la producción sustantiva o para la entrega de los resultados a los destinatarios. Por ejemplo, gestiones de rectoría, planificación, financiamiento, monitoreo, evaluación, control de gestión, suministro de infraestructura, reclutamiento y gestión de recursos humanos, logística, mantenimiento, etc.

En la MDP (Cuadro 1), puede observarse que las columnas desagregan algunos de los procesos de gestión típicos que, al cruzarse con las áreas (o subáreas) de gestión, generan celdas que identifican un determinado tipo de gestión para una determinada área funcional.

CRITERIOS DE EVALUACIÓN. Hasta aquí, la metodología permite determinar si resulta técnicamente posible proceder a descentralizar determinados procesos de gestión, en las distintas áreas funcionales en que las intendencias podrían asumir responsabilidades. Pero esa posibilidad no equivale a conveniencia, es decir, si bien sería admisible la descentralización de ciertos procesos de gestión, podría no ser conveniente por una variedad de razones.

Para ello, se propone utilizar varios criterios de evaluación. A tal efecto, el listado que se describe a continuación, si bien no es exhaustivo ni es el único que podría emplearse, ilustra en todo caso el tipo de consideraciones a tener en cuenta para determinar la conveniencia de descentralizar. Estos criterios deberían aplicarse en cada cruce (celda) de subárea funcional / proceso de gestión, utilizando una escala que tanto podría ser cuantitativa (v.g. 0 a 100 puntos) como cualitativa (v.g., Muy Conveniente, Conveniente, Ni Conveniente/ Ni Inconveniente, Inconveniente, Muy Inconveniente). 


\section{CUADRO 2}

EJEMPLOS DE ÁREAS FUNCIONALES DESAGREGADAS

\begin{tabular}{|c|c|}
\hline SALUD PÚBLICA & AGRICULTURA，GANADERÍA Y PESCA \\
\hline $\begin{array}{l}\text { Servicios de salud. } \\
\text { Medicina preventiva. } \\
\text { Higiene pública. } \\
\text { Profilaxis de las enfermedades. } \\
\text { Servicios privados de salud. } \\
\text { Programas integrados de salud. } \\
\text { Servicios médicos y sanitarios } \\
\text { especializados. } \\
\text { Salud de agentes o aspirantes a } \\
\text { ingresar al sector público. } \\
\text { Salud de inmigrantes. } \\
\text { Servicio médico escolar. } \\
\text { Administración de } \\
\text { establecimientos de salud. } \\
\text { Consultorios. } \\
\text { Instituciones. } \\
\text { Farmacias. } \\
\text { Laboratorios. } \\
\text { Hospitales. } \\
\text { Productos para la salud } \\
\text { y la sanidad. } \\
\text { Drogas. } \\
\text { Medicamentos. } \\
\text { Biológicos. } \\
\text { Dietéticos. } \\
\text { Insecticidas. } \\
\text { De tocador. } \\
\text { Aguas minerales. } \\
\text { Hierbas medicinales. } \\
\text { Material e instrumental } \\
\text { de aplicación médica. } \\
\text { Regulación de la salud. } \\
\text { Registro de establecimientos } \\
\text { sanitarios. } \\
\text { Patentes de sanidad. } \\
\text { Certificados de salud. } \\
\text { Medicina del trabajo. } \\
\text { Medicina del deporte. }\end{array}$ & 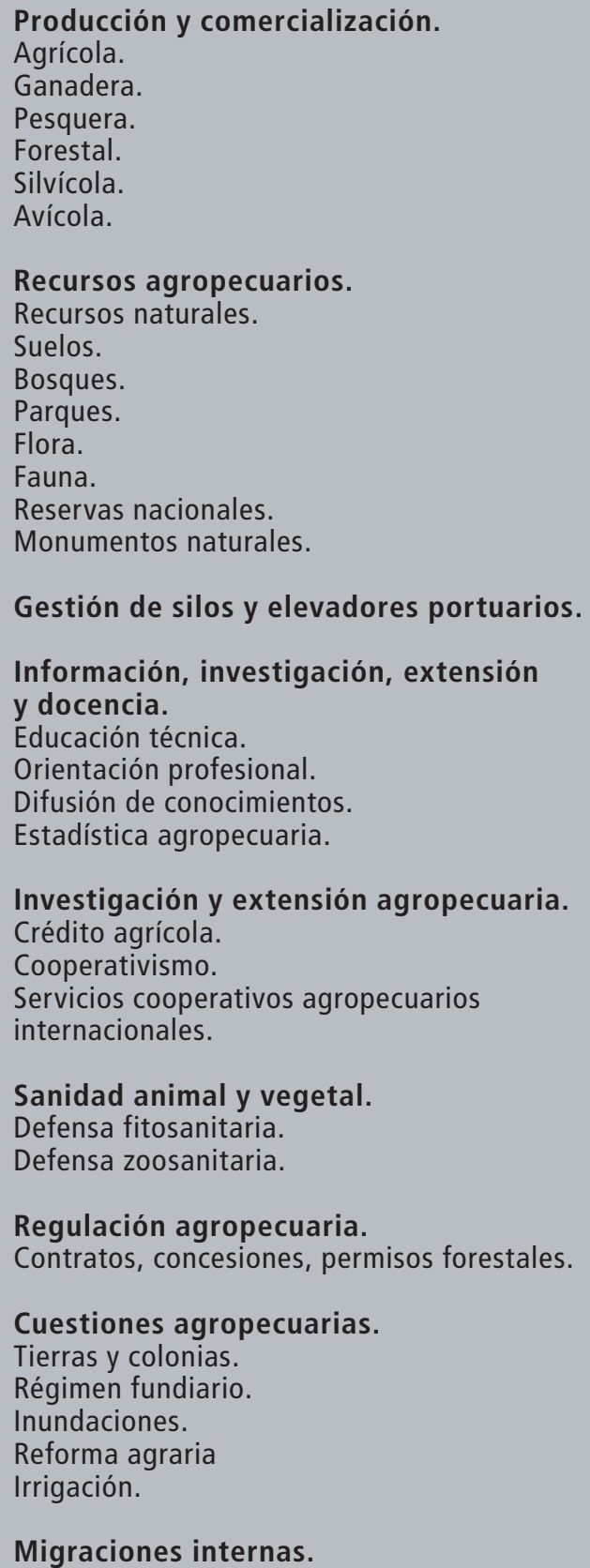 \\
\hline
\end{tabular}


Por ello, se sugiere que una vez descartadas todas aquellas celdas en las que se considera que no existe ninguna posibilidad de descentralizar algún proceso/área funcional, se proceda a evaluar la conveniencia de hacerlo con las que hubieran sido finalmente seleccionadas.

Resulta aconsejable utilizar una escala decimal, de modo que los valores atribuidos a cada criterio, puedan ser luego ponderados en función del peso o la importancia relativa asignada a cada criterio $^{13}$.

Se sugieren diez criterios, definidos de la siguiente forma:

1. Criticidad: grado en que no llevar a cabo la descentralización podría acarrear graves consecuencias sobre la eficiencia o efectividad de la respectiva gestión.

2. Efecto multiplicador o demostrativo: grado en que una posible experiencia de descentralización podría repercutir positivamente sobre el desempeño de la gestión, induciendo cambios "en cascada" de alcance más generalizado.

3. Complementariedad: grado en que la descentralización expandiría o complementaría otros programas o acciones en curso, potenciando sus efectos y contribuyendo al desarrollo de líneas de trabajo comunes a más de un área.

4. Voluntad política: grado en que se espera que la descentralización tend rá el apoyo y compromiso de los niveles políticos involucrados, para iniciarla y sostenerla en el tiempo.

5. Capacidad técnica disponible: grado de disponibilidad actual o futura de recursos humanos y tecnologías requeridos para que el gobierno departamental pueda asumir la responsabilidad de la gestión.

6. Impacto económico-financiero: magnitud de los recursos presupuestarios adicionales que exigiría la puesta en marcha de un proceso de descentralización en el área funcional en cuestión.

13. Si todos los criterios "pesaran" lo mismo, en una escala 0-100 cada uno tendría 10 puntos en la ponderación. Pero si los criterios tienen distinta prioridad o importancia, el más alto podría tener un peso de, por ejemplo, 25 puntos, y el más bajo de 3 o 4 puntos, con valores intermedios para los demás criterios hasta sumar 100 puntos en total. 
7. Riesgos: grado de incertidumbre respecto a las consecuencias de proceder a la descentralización, teniendo en cuenta la posible incidencia de factores tecnológicos, culturales, políticos o contextuales.

8. Compatibilidad política: medida en que la descentralización resulta congruente con los lineamientos u orientaciones políticas fijados por el gobierno de turno.

9. Legitimidad: grado de aceptación y respaldo de actores estratégicos a la decisión de descentralizar, en función de su visibilidad e impacto sobre la situación vigente al evaluar tal decisión.

10. Impacto sobre la gestión: efecto esperado sobre el desempeño de la gestión, como resultado de la descentralización.

De este modo, a cada "celda remanente" luego de la depuración se le asignarían puntajes según cada uno de estos criterios. De acuerdo con el puntaje total obtenido en cada celda, se adoptará la decisión que convenga respecto a descentralizar o no las subáreas funcionales y procesos involucrados.

ACCIONES DE DESARROLLO INSTITUCIONAL. Una vez adoptada la decisión de descentralizar, restaría considerar si para los casos seleccionados (es decir, las celdas resultantes de los cruces entre subárea y procesos de gestión), la iniciativa se llevará a cabo en la totalidad de los departamentos o sólo en algunos, que para tales efectos se considerarían "casos piloto". Esta última modalidad es bastante habitual en la práctica internacional, ya que permite comprobar si un nuevo estilo de gestión permite lograr los resultados positivos buscados con su adopción, para luego generalizar su aplicación. Una implementación limitada permite, además, aprender de los posibles errores de diseño y efectuar a tiempo los ajustes o correcciones necesarios. De este modo, se minimiza el riesgo de que un eventual fracaso en la concepción del esquema o en su implantación produzca consecuencias negativas de mucho mayor alcance.

Sin embargo, no siempre es posible optar por este procedimiento piloto de prueba y error. En ciertos casos, pueden existir restricciones constitucionales o legales que impidan o condicionen la posibilidad de descentralizar ciertas gestiones sólo a determinados departamentos, sin hacerlo para la totalidad. Esta circunstancia deberá ser analizada caso a caso. 
Por último, sea que la descentralización se lleve a cabo a través de experiencias piloto o en forma generalizada, es importante considerar previamente qué clase de acciones de desarrollo institucional deberían encararse para asegurar que se contará con la capacidad de gestión requerida, según la subárea funcional y tipo de procesos involucrados. Estas acciones podrían ser conducidas tanto por el gobierno nacional, a través de un programa de fortalecimiento institucional de la gestión departamental, como de proyectos de desarrollo ejecutados por las propias intendencias.

Existen numerosas metodologías para diseñar y ejecutar estos programas y proyectos. En líneas generales, la mayoría parte de una evaluación de las tareas o actividades que deben realizarse para completar una determinada gestión, para luego identificar probables déficit de capacidad institucional que podrían llegar a dificultar o impedir la ejecución de esas tareas. A partir de la sistematización de esos déficit, el programa de fortalecimiento institucional incluiría el diseño de normativas, la obtención y asignación de recursos humanos y materiales, la capacitación del personal, la contratación de consultoría especializada, el rediseño de estructuras organizativas y la reasignación de responsabilidades, etc. ${ }^{14}$.

\section{C O N C L US I O N E S}

El gobierno nacional uruguayo inició con decidido entusiasmo un proceso de descentralización de características sui generis, cuyo escenario definitivo no fue claro de entrada. Sin duda, comprendió la necesidad de reducir el excesivo centralismo de la administración pública nacional y de articular más eficazmente la acción de sus instituciones en el territorio. También intuyó que era necesario crear un tercer nivel de gobierno, al que habría que transferir ciertas responsabilidades de gestión, pero la naturaleza y alcances de las mismas no fueron del todo claras, razón por la cual las alcaldías no tienen definidas plenamente sus competencias.

Es posible que detrás de estas decisiones hayan pesado consideraciones que no se relacionaban tanto con la voluntad de transferir cometidos al segundo (o al tercer) nivel de gobierno, sino de acercar más la gestión del gobierno central a las localidades. Sin negar protagonismo a las intendencias, se buscó desconcentrar la gestión y mejorar la coordinación territorial, tanto 
horizontal (entre sus unidades ejecutoras) como vertical (con los otros niveles de gobierno y la sociedad civil).

Lo cierto es que más que descentralizar, la desconcentración de la gestión del gobierno nacional tendió a crear mayor institucionalidad en el territorio y a lograr una mejor articulación de sus servicios en los planos regional, intersectorial einterinstitucional. Creció de este modola densidad del aparato organizacional del Estado nacional en los departamentos, generándose una permanente búsqueda de fórmulas que permitieran fortalecer los procesos de formulación, ejecución y evaluación de políticas, a través de diversos tipos de arreglos institucionales (mesas, nodos, acuerdos, etc.).

Se trató, por otra parte, de aprovechar las oportunidades creadas por la disponibilidad de financiamiento externo no reembolsable, como el de la Unión Europea, o de organismos internacionales o multilaterales, como el Banco Interamericano de Desarrollo (BID) o el PNUD, para dar apoyo a la creación de unidades ejecutoras de proyectos de desarrollo en diversos campos de la gestión pública. Estas oportunidades favorecieron el lanzamiento de iniciativas y proyectos, en los que se buscó asociar los recursos y esfuerzos de organizaciones gubernamentales y privadas para complementar las actividades permanentes y rutinarias de diversas agencias gubernamentales. A la vez, si bien estas modalidades de gestión no implicaron sustraer responsabilidades de gestión al gobierno central, se vieron limitadas en cuanto a su ejecución a los recursos que en cada caso hicieron posible su puesta en marcha.

Nada permite suponer que el gobierno nacional se encamine hacia un proceso de descentralización en sentido estricto. La fallida creación de la figura de los coordinadores departamentales y regionales, hace suponer que se tiende a afianzar la labor del gobierno nacional, admitiendo la posible participación de las intendencias en algunos aspectos especializados de la gestión.

Dada la enorme variedad de roles y formas de participación que tienen (y podrían llegar a tener) los gobiernos departamentales dentro de ese margen de actuación acordado por el gobierno nacional, resulta difícil recomendar componentes de políticas nacionales posibles de ser transferidas al segundo nivel de gobierno o proponer diseños institucionales apropiados para ello.

En lugar de ello, hemos estudiado a fondo una experiencia -Nodos de Salud en Tacuarembó- que ilustra adecuadamente las tendencias señaladas, en tanto reúne aspectos de desconcentración territorial, articulación 
interinstitucional y diseño de un esquema de gestión innovador. El objetivo fue tratar de determinar no sólo las razones que explican el éxito de esa experiencia, sino también su posible continuidad y viabilidad, a raíz de la renovación y ampliación de los acuerdos logrados entre sus socios institucionales. La conclusión a la que arribó nuestro análisis fue que, si bien este tipo de esquemas resulta atractivo e innovador, descansa sobre bases excesivamente frágiles, por lo cual la posibilidad de su adopción en otros casos debería depender del test de los resultados logrados con la propia experiencia.

A partir de este análisis se trató de extraer algunas enseñanzas que permitieran, al menos, identificar los factores que deberían ser considerados, en caso de adoptarse la decisión de ampliar los alcances de una política de descentralización strictu senso. En esta hipótesis, una de las conclusiones de nuestro estudio ha sido que la creciente desconcentración territorial de la gestión estatal podría ser un paso necesario en el camino de la descentralización, en la medida en que crea capacidades de gestión localizadas en el territorio y, de este modo, asegura la disponibilidad de recursos humanos, prácticas y sinergias institucionalizadas, que resultarían imprescindibles en caso de adoptarse la decisión de descentralizar.

Sin embargo, como no resultaba posible ir mucho más allá en términos de efectuar recomendaciones para otras áreas funcionales de la gestión pública, dada la heterogeneidad y especificidad de sus respectivos requerimientos, se prefirió concluir este estudio proponiendo una metodología que podría ser utilizable, sin distinción de áreas o procesos de gestión, en el caso de que la hipótesis de descentralización se concretara finalmente. Esta metodología, basada en la que hemos denominado Matriz de Descentralización Prospectiva, permite a nuestro juicio llevar a cabo un riguroso razonamiento lógico que permita decidir en qué áreas o sub áreas funcionales y para qué procesos de gestión, sería posible y deseable avanzar en esa dirección. También permite aplicar criterios para decidir su respectiva conveniencia, así como para prever las acciones de fortalecimiento institucional que aseguren su éxito. Creemos que esta propuesta es mucho más relevante que recomendar la adopción de decisiones concretas, cuando aún no se evidencian claras orientaciones políticas que reflejen una voluntad de descentralizar. 


\section{RE F E R E N C I A S B I B L I O G RÁ F I C A S}

Convenio por una red de nodos de salud de Tacuarembó. http://www.mides.gub. uy/innovaportal/file/12574/1/convenio_red_nodos_de_salud_tacuarembo.pdf

Curto, Sergio (2004): El rescate de la esencia original, El Diario Médico, Uruguay, octubre http://www.smu.org.uy/publicaciones/eldiariomedico/n60/PAG-8.PDF.

Diario El Avisador de Tacuarembó (2008): Se firmó convenio para mejorar la atención primaria de salud, Uruguay, 7 de julio.

Dibarbourde Icasuriaga, Hugo. (s/f): "La atención primaria en salud (APS) en Uruguay, http://www.smu.org.uy/elsmu/organismos/ces/cuadernos/cuadernos3/ art8.pdf

Esteves, José (2011): Asistencia en Salud a 16.627 personas de zonas carenciadas, Diario El País, Uruguay, 18 de abril. http://www.elpais.com.uy/110603/pciuda-570657/ ciudades/Amplian-plan-de-Nodos-de-Salud-/

Gómez, Jackeline, et. al. (s/f): APS La experiencia del hospital de Tacuarembó. http://www.smu.org.uy/elsmu/organismos/ces/cuadernos/cuadernos3/art10.pdf

Hjortdahl, P. y Laerum, E. (1992): Continuity of care in general practice: effect on patient satisfaction, British Medical Journal, Londres.

Informe Uruguay (2002): OPS reconoció a Tacuarembó por la calidad de la atención primaria de la salud, Año 1, No 1, Uruguay, 15 de noviembre. http://personales.com/ uruguay/montevideo/informeuruguay/articulos/Tacuar.htm

Intendencia Municipal de Tacuarembó (2004): Estudio de Prefactibilidad de una Terminal de Cargas y Zona Industrial en la Ciudad de Tacuarembó, Informe Final, Presidencia de la República, Oficina de Planeamiento y Presupuesto CSI Ingenieros SRL, Montevideo.

Lazarov Luís, et. al. (2008): Reestructura del primer nivel de atención, Cuadernos de CES 1, SMU, marzo.

MSP y UNICEF (1987): Atención Primaria de la Salud, Documento $N^{\circ} 1$, Montevideo.

Navarro, Vicente (1984): A critique of the ideological and political position of the Brandt Report and the Alma Ata Declaration, International Journal of Health Services.

OMS-WONCA (1994): Hacer que la práctica médica y la educación médica sean más adecuadas a las necesidades de la gente: la contribución del médico de familia, Conferencia conjunta, London, Ontario, Canadá, Noviembre.

Oszlak, Oscar (1989), El Estado Nacional en el Interior: significación e impactos, Administración Pública y Sociedad, Nº 3, Universidad Nacional de Córdoba, IIFAP, Julio. 
Oszlak, Oscar y Orellana, Eduardo (1993), El Análisis de la Capacidad Institucional: aplicación de la metodología SADCI. Disponible en formato electrónico en www. oscaroszlak.org.ar

Reforma de la Salud (2007): Sistema Integrado de Salud, Sindicato Médico del Uruguay, http://www.smu.org.uy/sindicales/documentos/snis/

Rodríguez García, Susana (2010): Priorizan la atención primaria de Salud en Uruguay", Boletín Al Día, 6 de septiembre. http://boletinaldia.sld.cu/aldia/2010/09/06/ priorizan-la-atencion-primaria-de-salud-en-uruguay/

Thompson, James D. (1967, 2003). Organizations in Action: Social Science Bases of Administrative Theory. Transaction Publishers, New York

Turnes, Antonio L. (2011): Cómo nació la atención primaria de salud en el Uruguay, Diario Salud.net, 19 de julio.

http://www.diariosalud.net/index.php?option=com content\&task=view\&id=2378\&Itemid=525

Uruguay Integra (2011): El trabajo de tres socios en el territorio, http://www. uruguayintegra.gub.uy/novedades/ministerios-socios-territorio. 
